\title{
Alteraç̃̃es patológicas em potros infectados por Actinobacillus equuli subsp. haemolyticus
}

\author{
Pathological changes in foals infected with Actinobacillus equuli subsp. haemolyticus
}

\author{
Danilo Carloto Gomes ${ }^{\mathrm{I}}$ Saulo Petinatti Pavarini ${ }^{\mathrm{I}}$ Pedro Miguel Ocampos Pedroso ${ }^{\mathrm{I}}$ \\ Hugo Henrique Ferreira ${ }^{I}$ Tatiane Terumi Negrão Watanabe ${ }^{\mathrm{I}}$ Marcos José Pereira Gomes $^{\mathrm{II}}$ \\ David Driemeier $^{*}$
}

\begin{abstract}
Neste trabalho, são descritos dois casos fatais de septicemia com lesões embólicas causadas por Actinobacillus equuli subsp. haemolyticus em potros recém-nascidos. Em um dos animais, foram observados, na necropsia, pequenos nódulos esbranquiçados de aproximadamente $0,2 \mathrm{~cm}$ de diâmetro na cortical dos rins e no outro havia uma área de coloração acinzentada no lobo diafragmático esquerdo do pulmão. As principais alterações microscópicas observadas no primeiro animal foram rins com infiltrado inflamatório multifocal a coalescente acentuado, com predomínio de neutrófilos, associado com áreas basofílicas levemente granulares compostas por grumos bacterianos. No segundo animal, o pulmão apresentava infiltrado inflamatório neutrofílico, edema, congestão e colônias bacterianas intravasculares. Em ambos os casos, colônias bacterianas foram encontradas disseminadas por vários órgãos incluindo capilares cerebrais. Nos dois casos foi isolado e identificado A. equuli subsp. haemolyticus.
\end{abstract}

Palavras-chave: Actinobacillus equuli subsp. haemolyticus, septicemia, patologia, potros.

\section{ABSTRACT}

This paper describes two fatal cases of embolic and septicaemic lesions caused by Actinobacillus equuli subsp. haemolyticus in two newborn foals. In one foal was observed at necropsy small whitish nodules of approximately $0,2 \mathrm{~cm}$ in diameter on the renal cortex and the other foal had an area of gray color in the left diaphragmatic lobe of the lung. The main histologic changes were observed in the first foal kidneys with multifocal to coalescing inflammatory suppurative infiltrates associated with slightly granular basophilic bacterial colonies. In the second animal the lung showed neutrophilic inflammatory infiltrate, edema, congestion and presence of intravascular bacterial colonies. In both cases, the bacteria were disseminated by several organs including cerebral capillary cerebral. In both cases A. equuli subsp. haemolyticus was isolated and identified.

Key words: Actinobacillus equuli subsp. haemolyticus, septicaemia, pathology, foal.

O Actinobacillus equuli é um bacilo Gram negativo, importante causador de mortes em potros em diversos países (BAKER, 1972; PLATT, 1973, RYCROFT etal., 1998; SCHLAFER \& MILLER, 2007).É uma bactéria oportunista, com baixa patogenicidade, que causa infecção e morte quando condições peculiares são permitidas (RYCROFT \& GARSIDE, 2000). Têm sido relatados casos esporádicos dessa afecção em rebanhos ou na forma de pequenos surtos (BAKER, 1972).

Nos equinos adultos, o A. equuli é isolado normalmente da cavidade oral e faringe sem aparentemente causar lesão, sendo raramente isolado de placenta, swabs de útero, vagina e cérvix (PLATT, 1973; RYCROFT \& GARSIDE, 2000). Nos potros, o agente é frequentemente isolado de articulações, rins, pulmão e intestino (STEWART et al., 2002).

'Departamento de Patologia Clínica Veterinária, Universidade Federal do Rio Grande do Sul (UFRGS). Av. Bento Gonçalves, 9090, 91540-000, Porto Alegre, RS, Brasil. E-mail: davetpat@ufrgs.br. *Autor para correspondência.

"Laboratório de Bacteriologia Clínica e Veterinária, UFRGS, Porto Alegre, RS, Brasil. 
Em cavalos adultos, o A. equuli é considerado agente causador de efusão pleural com pleuropneumonia, pleurite (PLATT, 1973; COLLINS et al., 1994), peritonite (PLATT, 1973; COLLINS et al., 1994; PATTERSON-KANE et al., 2001), hemorragia pulmonar (PUSTERLA et al., 2008), endocardite valvular (AALBÆK et al., 2007), septicemia (PATTERSONKANE et al., 2001) e abortos (SCHLAFER \& MILLER, 2007). Os animais jovens quando infectados apresentam geralmente prostração e morte repentina (BAKER, 1972; PLATT 1973; STEWART et al., 2002). Também são relatados casos de febre, diarreia (STEWART et al., 2002) e celulite facial, embora a última seja pouco comum (CASTAGNETTI et al., 2008). Após o início das manifestações clínicas, o prognóstico é desfavorável (BAKER, 1972). O objetivo do presente trabalho é descrever a ocorrência e as alterações patológicas de dois casos de embolia séptica por Actinobacillus equuli subsp. haemolyticus em potros recém-nascidos, no Estado do Rio Grande do Sul.

Dois potros foram encaminhados ao Setor de Patologia Veterinária da Universidade Federal do Rio Grande do Sul (SPV-UFRGS) para realização de necropsia. Os históricos referentes aos animais foram obtidos junto aos médicos veterinários responsáveis pelos casos. Durante as necropsias, fragmentos de diversos órgãos foram coletados e fixados em solução de formalina tamponada a $10 \%$, processados de forma rotineira para histologia, emblocados em parafina, cortados a $5 \mu \mathrm{m}$ de espessura, corados pela hematoxilina e eosina (HE) e coloração especial de Brown-Hopps modificada (Gram) para identificação de bactérias Gram positivas e Gram negativas (PROPHET et al., 1992). Além disso, fragmentos de rim (potro 1) e pulmão (potro 2) foram coletados, mantidos refrigerados e enviados para cultivo e isolamento bacteriano. Essas amostras foram maceradas e inoculadas em placas de ágar com sangue ovino 7\%; MacConkey e caldo BHI (Brain and Heart Infusion broth). As placas foram incubadas em aerobiose e em microaerofilia à temperatura de $37^{\circ} \mathrm{C}$.

Os dois animais encaminhados ao SPVUFRGS eram provenientes do Município de Porto Alegre, Rio Grande do Sul. O primeiro caso (potro 1) era um equino, fêmea, da raça Crioula, com três dias de vida e de acordo com o proprietário, sofria rejeição ao mamar. O segundo caso (potro 2) era um equino, macho, da raça Mangalarga Marchador, com um dia de vida. De acordo com o histórico, o animal nasceu de parto normal, porém prematuro (311 dias de gestação) e a placenta não apresentava alterações. O potro aparentemente apresentava-se hígido, tendo mamado normalmente. No entanto, foi encontrado morto na manhã do dia seguinte.
Durante o exame macroscópico do potro 1, foram observados nódulos esbranquiçados de aproximadamente $0,2 \mathrm{~cm}$ de diâmetro na superfície renal e ao corte estes eram mais evidentes na região cortical (Figura 1A). No potro 2, observou-se apenas uma área de coloração acinzentada localizada no lobo diafragmático esquerdo do pulmão.

No exame microscópico do potro 1, observou-se, no rim, infiltrado inflamatório multifocal a coalescente acentuado com predomínio de neutrófilos, associado a áreas basofílicas de aspecto levemente granular compatível com colônias bacterianas. Esse material estava presente também no interior de diversos glomérulos (Figura 1B). No fígado, foram visualizadas múltiplas áreas de infiltrado inflamatório discreto predominantemente neutrofílico também associado às colônias bacterianas. No potro 2 , foram visualizados, no pulmão, infiltrado inflamatório neutrofílico, multifocal, moderado, edema e congestão difusos e moderados. Estruturas granulares basofílicas compatíveis com colônias bacterianas foram visualizadas no interior de vasos do parênquima pulmonar (Figura 1C), do córtex cerebral, do cerebelo e de ocasionais glomérulos. Na coloração de Gram, as estruturas basofílicas granulares observadas no interior de vasos e nos rins coraram-se de vermelho rosado, confirmando serem colônias de bactérias Gram negativas (Figura 1D). Nos fragmentos de rim (potro 1) e pulmão (potro 2), após 24 horas da inoculação nas placas, houve o crescimento de colônias pequenas, convexas, hemolíticas, não pigmentadas, viscosas e aderentes ao meio sólido. Pelo cultivo em MacConkey, foi evidenciado crescimento de um grande número de pequenas colônias circulares, lactoses positivas, as quais, após 48 horas de incubação, tornaram-se maiores. Por meio da coloração de Gram, foram evidenciados cocobacilos Gram negativos delicados, curtos, retos ou levemente encurvados. As características morfotintoriais, culturais e bioquímicas permitiram isolar e identificar o Actinobacillus equuli subsp. haemolyticus (QUINN et al., 1999; EUZÉBY 2009).

O diagnóstico de septicemia por Actinobacillus equuli subsp. haemolyticus nos dois casos apresentados foi baseado nos achados clínicos, patológicos e pelo isolamento do agente a partir de fragmento de rim e pulmão lesionados.

A via de infecção no potro pelo A. equuli ocorre pela cavidade oral, trato respiratório ou umbigo (RYCROFT \& GARSIDE, 2000), durante ou após o nascimento(RYCROFT \& GARSIDE, 2000; SCHLAFER \& MILLER, 2007). Outra hipótese é que a bactéria contamine o potro no útero, por invasão 


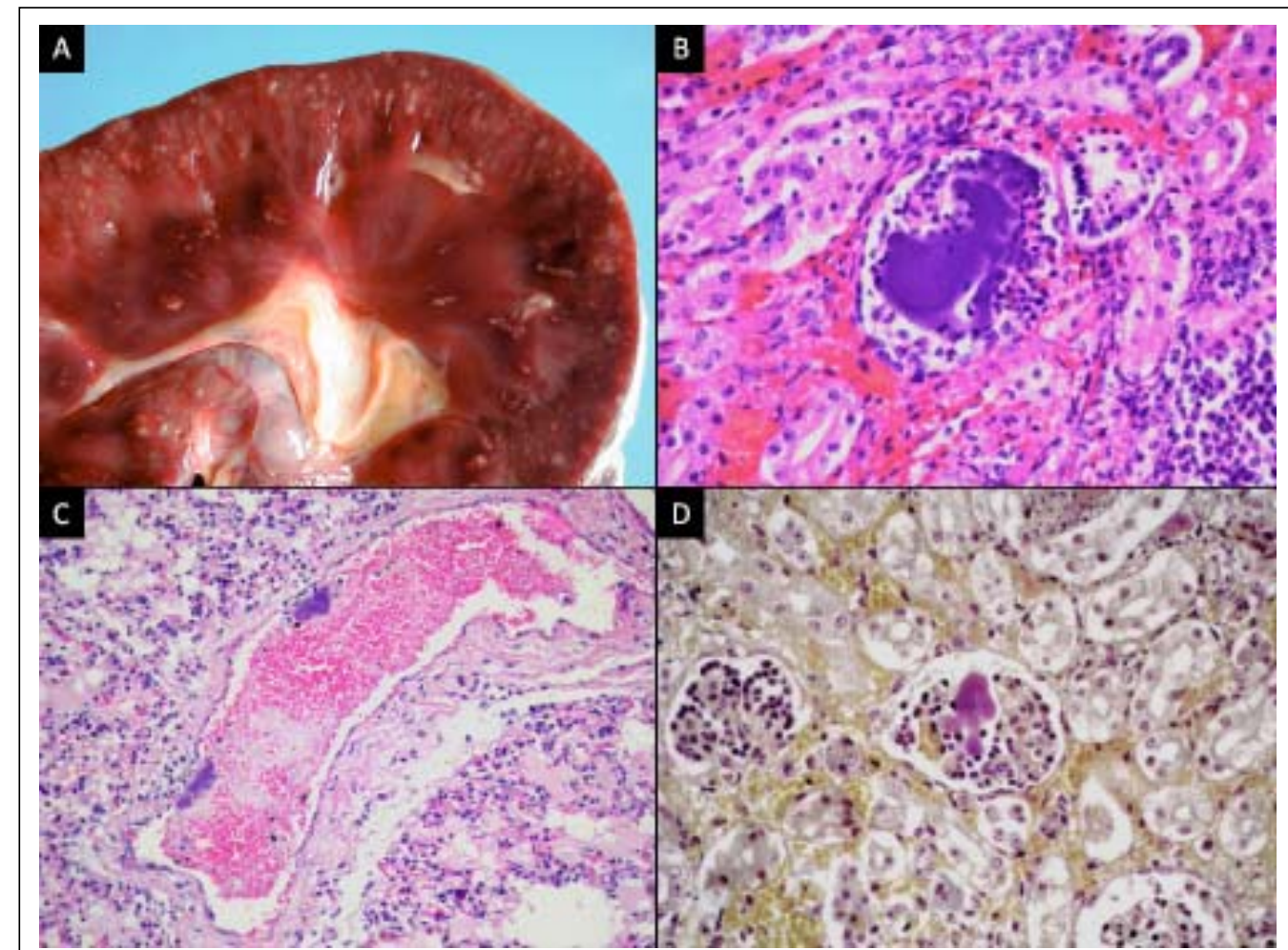

Figura 1 - Alterações patológicas em potros infectados por Actinobacillus equuli subsp. haemolyticus. A. Potro 1: Rim. Múltiplos pontos esbranquiçados, com predomínio na região cortical (Glomerulonefrite embólica por A. equuli subsp. haemolyticus). B. Potro 1: Rim. Material levemente granular, basofilíco compatível com colônias bacterianas cercado por infiltrado neutrofílico no interior do glomérulo, HE, obj. 40. C. Potro 2: Pulmão. Material levemente granular, basofilíco no interior de vasos, compatível com colônias bacterianas. HE, obj. 20. D. Potro 1: Rim. Colônias bacterianas Gram negativas evidentes no interior de glomérulos. Gram técnica de Brown-Hopps, obj. 40.

transplacentária (KOWALSKI, 1998; SCHLAFER \& MILLER, 2007) causando abortos e mortes por septicemia logo após o nascimento. Acredita-se que o potro 2 tenha sido infectado por invasão transplacentária já que este morreu logo após o nascimento. Potros que sobrevivem por três a quatro dias desenvolvem lesões em diversos tecidos, em razão da bacteremia (SCHLAFER \& MILLER, 2007), fato observado no potro 1 , que sobreviveu três dias e apresentava lesões em diversos tecidos.

Um dos principais achados patológicos relacionados a quadros de septicemia por $\boldsymbol{A}$. equuli em equinos é a glomerulonefrite embólica, caracterizada por múltiplas pequenas nodulações esbranquiçadas dispersas no parênquima renal (NEWMAN et al., 2007; SCHLAFER \& MILLER, 2007), achado visto no potro 1. A presença de material basofílico levemente granular no interior de glomérulos, fígado, pulmão e vasos sanguíneos, associado ou não ao infiltrado inflamatório composto predominantemente por células polimorfonucleares observados nos potros $1 \mathrm{e} 2$ foram achados semelhantes aos de PLATT (1973).
Os principais agentes bacterianos relacionados a quadros de septicemia em potros são A. equuli, Escherichia coli, Streptococcus sp e Klebsiella sp, sendo necessário, para confirmação do diagnóstico o isolamento do agente a partir de amostras de sangue ou tecidos afetados (HENTON, 2004). No presente relato o Actinobacillus equuli subsp. haemolyticus foi isolado nos dois casos.

Fatores predisponentes têm papel fundamental na patogênese dos casos de infecção em potros durante a primeira semana de vida. Um fator predisponente considerado importante é a falha na transferência passiva de imunoglobulinas, por meio do colostro (PLATT, 1973). Na infecção neonatal em potros, a deficiência imunológica é mais importante que a patogenicidade da bactéria (RYCROFT et al., 1998). No presente relato, os dados do histórico indicam que ambos os animais possam ter sofrido falhas na transferência passiva de imunoglobulinas. Alguns fatores reduzem a efetividade da colostragem, como morte da égua, atraso ou falha na ingestão do colostro, potros prematuros e deformidades na boca (PLATT, 
1973; SANCHEZ, 2005). O potro 2 era uma animal prematuro, fato que pode ter contribuído para a falha na transferência passiva pelo colostro.

Uma das principais causas de mortalidade em potros é a evolução do quadro de infecção para septicemia (PLATT, 1973), e este trabalho demonstra que o Actinobacillus equuli subsp. haemolyticus deve ser considerado em casos de mortes neonatais como agente causador de septicemia no Estado do Rio Grande do Sul, Brasil.

\section{REFERÊNCIAS}

AALBÆK, B. et al. Actinobacillus equuli subsp. equuli associated with equine valvular endocarditis. Acta Pathologica, Microbiologica et Immunologia Scandinavica, v.115, n.12, p.1437-1442, 2007. Disponível em: <http://www3.interscience.wiley.com/cgi-bin/fulltext/ 117978641/PDFSTART>. Acesso em: 20 abr. 2010. doi: 10.1111/ j.1600-0463.2007.00768.x.

BAKER, J.R. An outbreak of neonatal deaths in foals due to Actinobacillus equuli. Veterinary Record, v.90, n.22, p.630633, 1972.

CASTAGNETTI, C. et al. Facial cellulitis due Actinobacillus equuli infection in a neonatal foal. Veterinary Record, v.162, n. 11, p. 347-349, 2008 .

COLLINS, M.B. et al. Pleural effusion associated with acute and chronic pleuropneumonia and pleuritis secondary to thoracic wounds in horse: 43 cases (1982-1992). Journal of American Veterinary Medical Association, v.205, n.12, p.1753-1758, 1994.

EUZÉBY, J.P. List of prokaryotic names with standing in nomenclature. Acessado em 15 de jul. 2009. Online. Disponível em: <http://www.bacterio.cict.fr/bacdico/aa/ equulibis.html>.

HENTON, M.M. Actinobacillus equuli infections. In: COETZER, J.A.W.; TUSTIN, R.C. Infectious diseases of livestock. 2.ed. New York: Oxford University, 2004. V.3, cap.159, p.1652-1654.

KOWALSKI, J.J. Mechanisms of infectious disease. In: REED, S.M.; BAYLY, W.M. Equine Internal Medicine. Philadelphia: Saunders, 1998. Cap.2, p.61-123.

NEWMAN, S.J. et al. Urinary system. In: McGAVIN, M.D.; ZACHARY, J.F. Pathologic basis of veterinary disease. 4.ed. St. Louis: Mosby Elsevier, 2007. Cap.11, p.613-691.

PATTERSON-KANE, J.C. et al. Septicemia and peritonitis due to Actinobacillus equuli infection in an adult horse.
Veterinary Pathology, v.38, n.2, p.230-232, 2001. Disponível: $<$ http://vet.sagepub.com/content/38/2/230.full $>$. Acesso em: 20 abr. 2010. doi: 10.1354/vp.38-2-230.

PLATT, H. Septicemia in the foal. A review of 61 cases. British Veterinary Journal, v.129, n.3, p.221-229, 1973.

PROPHET, E.B. et al. Laboratory methods in histotechnology. Washington: American Registry of Pathology, 1992. 279p.

PUSTERLA, N. et al. Fatal pulmonary hemorrhage associated with RTX toxin-producing Actinobacillus equuli subspecies haemolyticus infection in an adult horse. Journal of Veterinary Diagnostic Investigation, v.20, n.1, p.118-121, 2008.

QUINN, P.J. et al. Actinobacillus species. In: Clinical veterinary microbiology. Edimburg: Mosby, 1999. Cap.21, p.248-253.

RYCROFT, A.N. et al. Serum antibody in equine neonatal septicemia due to Actinobacillus equuli. Veterinary Record, v.143, n.9, p.254-255, 1998 .

RYCROFT, A.N.; GARSIDE, L.H. Actinobacillus species and their role in animal disease. Veterinary Journal, v.159, n.1, p.18-38, 2000. Disponível em: < http://www.sciencedirect.com/ science? ob=ArticleURL\& udi=B $6 \mathrm{WXN}-45 \mathrm{BCF} 4 \mathrm{~J}-$ $1 \mathrm{X} \&$ _user $=687304 \&$ _coverDate $=01 \% 2 \mathrm{~F} 31 \% 2 \mathrm{~F} 2000 \&$ \&do $\mathrm{c}=1 \&$ \&mt $=$ high \&_orig $=$ search \&_sort $=\mathrm{d} \&$ _docanchor $=\& \mathrm{v}$ iew $=$ c\&_acct $=$ C $000037798 \&$ _version $=1 \&$ \&urlVersion $=$ $0 \&$ useri $\bar{d}=687304 \& \mathrm{md} 5=6078 \mathrm{cb} 56 \mathrm{ab} 807 \mathrm{f} 3 \mathrm{~b} 6 \mathrm{aee} 924489078 \mathrm{cab}>$. Acesso em: 20 abr. 2010. doi:10.1053/tvj1.1999.0403.

SANCHEZ, L.C. Equine neonatal sepsis. Veterinary Clinics of North America: Equine Practice, v.21, n.2, p.273-293, 2005. Disponível em: <http://www.sciencedirect.com/ science? ob=ArticleURL\& udi=B7RM8-4GR2R2X$5 \&$ _user $=687304 \&$ _coverDate $=08 \% 2 \mathrm{~F} 31 \% 2 \mathrm{~F} 2005 \&$ rdoc $=1$ $\&$ fmt $=$ high \& orig $=$ search \& sort $=\mathrm{d} \&$ docanchor $=\& \mathrm{v}$ ie $=$ $=c \&$ acct $=\overline{\mathrm{C}} 000037798 \&$ \& version $=1 \&$ _urlVersion $=0 \&$ userid $=687304 \& \mathrm{md} 5=\mathrm{ed} 558 \mathrm{~b} 5$ eaae $35 \mathrm{a} 6 \mathrm{c} 9868 \mathrm{~d} 2 \mathrm{fc} 3908 \mathrm{fb} 31>$. Acesso em: 20 abr. 2010. doi:10.1016/j.cveq.2005.04.007.

SCHLAFER, D.H.; MILLER, R.B. Female genital system. In: JUBB, K.V.F. et al. Pathology of domestic animals. 5.ed. San Diego: Academic, 2007. V.3, cap.4, p.429-564.

STEWART, A.J. et al. Actinobacillus sp. Bacteremia in foals: clinical signs and prognosis. Journal of Veterinary Internal Medicine, v.16, n.4, p.464-471, 2002. Disponível em: <http:/ /www3.interscience.wiley.com/cgi-bin/fulltext/119824387/ PDFSTART $>$. Acesso em: 20 abr. 2010. doi: 10.1111/j.19391676.2002.tb01266.x. 